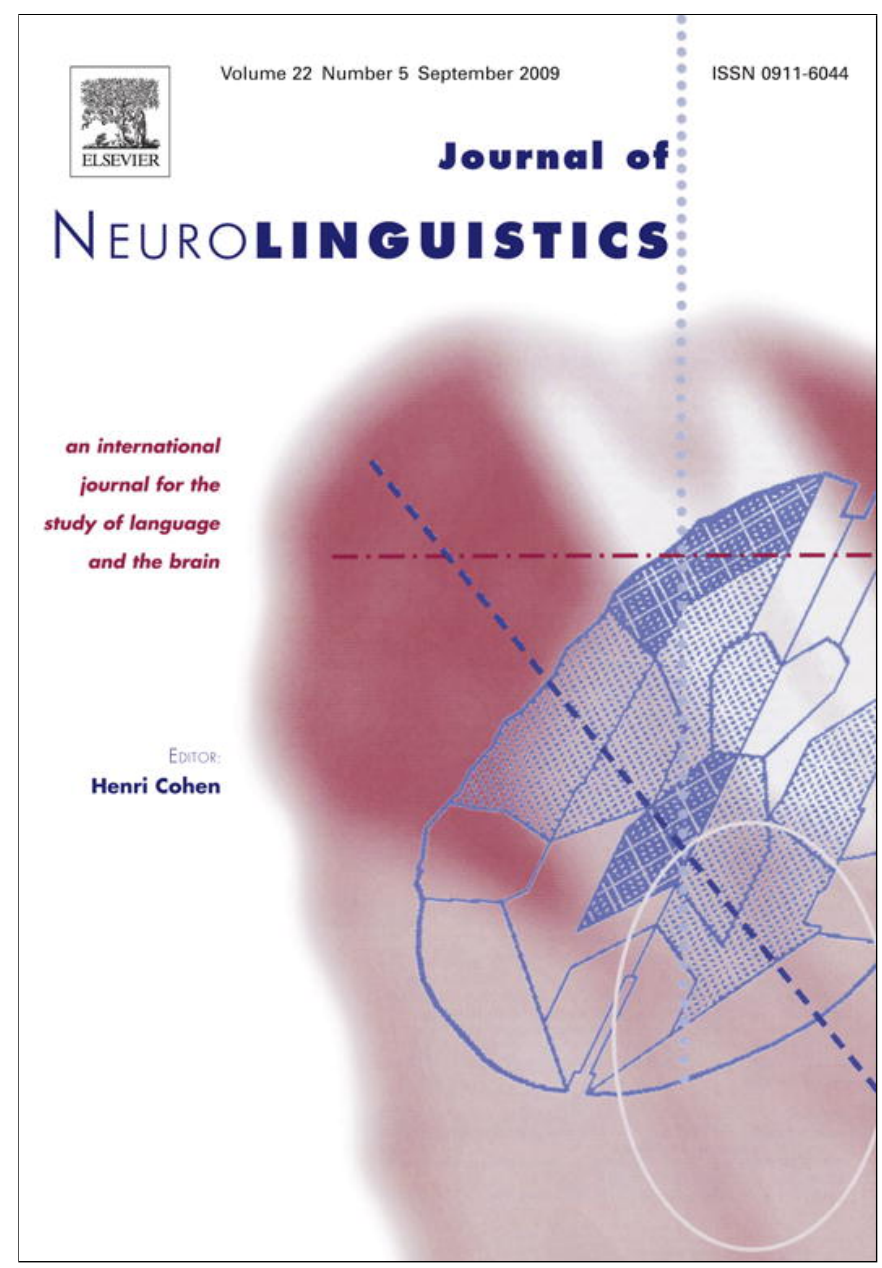

This article appeared in a journal published by Elsevier. The attached copy is furnished to the author for internal non-commercial research and education use, including for instruction at the authors institution and sharing with colleagues.

Other uses, including reproduction and distribution, or selling or licensing copies, or posting to personal, institutional or third party websites are prohibited.

In most cases authors are permitted to post their version of the article (e.g. in Word or Tex form) to their personal website or institutional repository. Authors requiring further information regarding Elsevier's archiving and manuscript policies are encouraged to visit:

http://www.elsevier.com/copyright 


\title{
Acquired stuttering in a 16-year-old boy
}

\author{
Catherine Theys ${ }^{\mathrm{a}, *}$, Astrid van Wieringen ${ }^{\mathrm{a}}$, Luc Tuyls ${ }^{\mathrm{b}}$, Luc De Nil ${ }^{\mathrm{a}, \mathrm{c}}$ \\ ${ }^{a}$ Katholieke Universiteit Leuven, Department of Neurosciences, Faculty of Medicine, ExpORL, Speech Language Pathology and \\ Audiology, Herestraat 49 bus 721, 3000 Leuven, Belgium \\ ${ }^{\mathrm{b}}$ Department of Neurology, CAZ Hospital Hasselt, Salvatorstraat 20, 3500 Hasselt, Belgium \\ ${ }^{\mathrm{c}}$ University of Toronto, Department of Speech-Language Pathology, 500 University Avenue, Room 160, M5G1V7 Toronto, Canada
}

\section{A R T I C L E I N F O}

\section{Article history:}

Received 5 November 2008

Received in revised form 10 February 2009

Accepted 15 February 2009

\section{Keywords:}

Acquired stuttering

Child

Rotavirus infection

Encephalitis

Case study

\begin{abstract}
A B S T R A C T
This case study describes a 16-year-old boy who started to stutter after a rotavirus infection followed by signs suggestive of a cerebellar encephalitis. It illustrates the fact that acquired stuttering can be observed in younger children and that it may be difficult to distinguish neurogenic from psychogenic forms of acquired stuttering in some cases. This is especially true following a disease that is not commonly associated with acquired stuttering. Speech, language and medical results of our patient are reported in detail. Similarities with previously reported cases and comparisons to (speech) characteristics of psychogenic and neurogenic stuttering will be discussed.
\end{abstract}

(c) 2009 Elsevier Ltd. All rights reserved.

\section{Introduction}

Acquired stuttering is a disorder characterized by stuttering-like disfluencies which appear gradually or suddenly in mostly adult patients who have no previous history of stuttering. It rarely occurs in children (e.g. Nass, Schreter, \& Heier, 1994; Yeoh, Lind, \& Law, 2006) and contrasts with developmental stuttering which normally has its onset between the age of 2 and 6 years (Bloodstein, 1995). Acquired stuttering can be differentiated in a neurogenic and a psychogenic form. Neurogenic stuttering typically occurs in adults following stroke, traumatic brain injury or neurodegenerative disease (De Nil, Rochon, \& Jokel, 2008; Theys, van Wieringen, \& De Nil, 2008). It has also been described following epilepsy (Michel et al., 2004), encephalitis (Chen \& Peng, 1993), use of medication (Movsessian, 2005), anorexia (Byrne, Byrne, \& Zibin, 1993) and other disorders that might affect brain function. In contrast,

\footnotetext{
* Corresponding author. Tel.: +32163304 79; fax: +3216330486.

E-mail address: catherine.theys@med.kuleuven.be (C. Theys).
} 
psychogenic stuttering most likely appears as a consequence of an emotional or psychological trauma (De Nil et al., 2008) and has been characterized as a conversion reaction (Mahr \& Leith, 1992). It often co-occurs with nonorganic somatic complaints, which may raise a suspicion of neurologic disease and thus complicate the differential diagnosis between neurogenic and psychogenic stuttering (Roth, Aronson, \& Davis, 1989).

In this paper we present the case of a 16-year-old boy who started to stutter following a rotavirus infection, accompanied by signs suggestive of a cerebellar encephalitis. This case illustrates the fact that acquired stuttering can be observed in younger children and that it may be difficult to distinguish neurogenic from psychogenic forms of acquired stuttering in some cases, especially following a disease that is not commonly associated with acquired stuttering.

\section{Case description}

At the age of 16, D. had a throat infection followed by episodes of vomiting, diarrhea and loss of consciousness. He was admitted to hospital where he was diagnosed as having a rotavirus infection. While he was admitted, he was short of breath and experienced elevated blood pressure. These symptoms were diagnosed as fear-triggered hyperventilation and D. was discharged from hospital after one week. Seventeen days later, he started experiencing neurological problems, including difficulties with normal daily activities (such as writing and getting dressed), reduced talkativity, episodes of crying, and mood changes. His body temperature dropped below $36^{\circ} \mathrm{C}$. In addition, he reported dizziness and headache. These signs lasted for a few days and an EEG and CT-scan were performed. Both were found to be within normal limits. Four days after the first occurrence of the neurological symptoms, D. additionally experienced loss of hand control, loss of consciousness (lasting for a few seconds) and naming difficulties. It was at that time that stuttering was first observed. According to D. and his parents the stuttering started suddenly and was not associated with an emotional or stressful event. On the contrary, D. expressed regret about the occurrence of his stuttering and of the other neurological symptoms because they interfered with the many activities he had planned for that period. The case history did not reveal evidence of past emotional or behavioral problems. According to D. and his mother, there was no history of stuttering in childhood, nor a family history of stuttering. However, he did receive one year of therapy for speech and language delay at the age of four. Additionally, he underwent an adenotonsillectomy at the age of three and a pharyngoplasty due to hypernasality at the age of five.

Over the next days the neurological symptoms worsened. There was further deterioration of speech and walking, and dizziness, headache and disturbance of equilibrium were reported, which led to admission to the emergency department of the hospital. At admission, he was focused into himself, did not speak and only showed minimal reactions to his environment. The EEG, ECG, NMR and lumbar puncture performed in the hospital were within normal limits, but since the symptoms were suggestive of cerebellar encephalitis, a treatment with Zovirax was started. Following the initiation of this drug treatment, the symptoms gradually improved and D. was discharged from the hospital 10 days later. When he returned home, the symptoms worsened again and he was referred to another hospital for further investigation. This time the attending neurologist concluded that there was an inconsistency in the clinical-neurological symptoms since she observed that $\mathrm{D}$. did not always stutter and that his loss of strength and gait disturbance disappeared when he was not aware of the examinations. Consequently, D. was referred for a psychiatric evaluation. This assessment led to insufficient indications to support a psychiatric diagnosis following the DSM-IV criteria (American Psychiatric Association, 2000). However, the psychiatrist concluded that it was not impossible that D.'s disease could have been intensified by some psychological factors since he was characterized as a sensitive boy in his puberty, and had some difficulties with the language courses in school. Because a straightforward diagnosis of either a neurological or psychiatric cause could not be made, the diagnosis of a somatoform disorder was given.

During his psychiatric evaluation, D. was assessed for the first time by a speech-language pathologist. During the assessment, his speech was reported to be continuously disfluent. D. remarked that his speech was more disfluent in the morning and evening when he was tired. He still dared to speak, even to strangers, but he found the stuttering very annoying and did not understand why the words 
and sentences that were ready in his head, were pronounced with such effort. In addition, the speech therapist noticed voice breaks, which were attributed to puberty.

Six weeks after the initial onset of the neurological symptoms, intensive rehabilitation was started. According to D. and his mother some spontaneous recovery of the neurological symptoms had already occurred before the treatment started. During the first two months of the rehabilitation, which took place during the summer holidays, D. received daily speech-language therapy, physiotherapy, hydrotherapy and occupational therapy. Speech therapy focused primarily on D.'s breathing pattern and the correct use of his voice. These exercises consisted of relaxation exercises, using abdominal breathing, using appropriate breath pauses when speaking, and prolonging sounds.

After two months there was improvement on all aspects and therapy frequency was reduced to once a week. During subsequent speech therapy D. mostly practiced reading texts with his newly acquired breathing pattern and he learned to make the transfer to spontaneous speech. According to the speech therapist there was good improvement in D.'s stuttering and voice quality.

One month after the onset of stuttering, D. was referred to the first author for a detailed evaluation. The results of this evaluation will be discussed in the following sections.

\section{Speech and language testing protocol}

D.'s speech and language were examined three times by the first author. The first test session took place when D. was 16 years 9 months old, one month after the onset of the stuttering. The second test session occurred when he was 17 years 1 month and the third and last test session took place one year later (age: 18 years 1 month). Between test sessions, telephone follow-ups were conducted. All speech and language examinations were video recorded. Speech samples were collected during spontaneous speech, reading, counting, naming days of the week and singing. For each test session, at least 350 words of D.'s spontaneous speech were transcribed for offline fluency analysis. Prolongations, blocks, and sound, syllable and monosyllabic word repetitions were identified as moments of stuttering. The disfluencies were measured as percentage of stuttered syllables and were rated by 2 of the authors (CT \& LDN) in order to assess interrater reliability, using the 'percent agreement index' (Cordes, Ingham, Frank, \& Ingham, 1992). Reliability measures on the total stuttering frequency were $98 \%$ for both spontaneous speech and reading. Stuttering severity was calculated based on the Stuttering Severity Instrument-3 (SSI-3, Riley, 1994). In addition, D. completed the Dutch translation of the Speech Situation Checklist - Emotional Reaction (SSC-ER, Brutten \& Vanryckeghem, 2003), Speech Situation Checklist - Speech Disruption (SSC-SD, Brutten \& Vanryckeghem, 2003), Behavior Checklist (BC, Brutten \& Vanryckeghem, 2003) and the S-scale (Stes, 1999). Because the case history revealed the presence of potential naming problems, the Boston Naming Test (Kaplan, Goodglass, \& Weintraub, 1983; Mariën, Mampaey, Vervaet, Saerens, \& De Deyn, 1998) was also administered.

\section{Results}

\subsection{First test session (age: 16 years 9 months)}

\subsubsection{Stuttering frequency}

D. stuttered on $33 \%$ of the syllables in spontaneous speech and on $56 \%$ during reading of a text. The stuttering frequency was $56 \%$ for naming the days of the week, $37 \%$ for counting and $61 \%$ for singing (see Table 1).

\subsubsection{Adaptation}

D. had a stuttering frequency of 56\% when he read the text 'De Kapitein' (Boey, 2000) for the first time. During the first test session, his stuttering frequency was $45 \%$ during the second reading and $40 \%$ during the last reading of the text. Thus a small adaptation effect was present since the stuttering frequency was reduced with $16 \%$ when comparing the third to the first reading. 
Table 1

Stuttering frequency (in \% stuttered syllables) during spontaneous speech, reading of a text, automatic speech (naming days of the week and counting) and singing for each of the three test sessions.

\begin{tabular}{llll}
\hline & 1st test session & 2nd test session & 3rd test session \\
\hline Spontaneous speech & $33 \%$ & $1 \%$ & $1 \%$ \\
Reading & $56 \%$ & $0 \%$ & $0 \%$ \\
Naming days of the week & $56 \%$ & $0 \%$ & 1 \\
Counting & $37 \%$ & $0 \%$ & $0 \%$ \\
Singing & $61 \%$ & $0 \%$ & $0 \%$ \\
\hline
\end{tabular}

Note. Naming days of the week was not performed during the last test session.

\subsubsection{Disfluency types and localization}

During spontaneous speech $81 \%$ of D.'s stutters were repetitions of sounds. Most typically, speech sounds were repeated twice but occasionally, the stutters could be up to nine repetitions long with increasing tension. Prolongations were present in $10 \%$ of the stuttered syllables, with word repetitions and blocks occurring in a minority of the stuttering moments (see Table 2). The distribution of the disfluency types during reading and fluency enhancing conditions (counting, naming days of the week and singing) was comparable to spontaneous speech. The disfluencies occurred in the initial position of the words in almost $90 \%$ of the stuttered instances. The remaining disfluencies were present in the medial position of the words (see Table 2).

\subsubsection{Secondary behaviors}

It was observed that D. often used short, agrammatical sentences (e.g. 'then April 30th and start fainting'). He also played with his hand on the table during speech, squinted his eyes, tensed the muscles in his face and moved his head forward during a stutter.

\subsubsection{Emotions and attitudes}

D. did not seem to be afraid of speaking and said not to avoid speaking. He scored comparable to non-stuttering subjects on the SSC-ER (Brutten \& Vanryckeghem, 2003). On the SSC-SD and the BC (Brutten \& Vanryckeghem, 2003), D.'s scores were in the range of those of stuttering subjects. He indicated that he found it particularly hard to say a sound or word that had proven to be difficult in the past. Concerning the behaviors associated with the stuttering, D. noticed that he spoke in a different way than usual, moved his hands and head, and protruded his lips during speech. On the S-scale (Stes, 1999) he had a very low score (6/39) which indicated that he did not react negatively to his stuttering.

\subsubsection{Stuttering severity}

Stuttering severity was calculated with the SSI-3 (Riley, 1994) and was rated as moderate (percentile: 61-77).

\section{Table 2}

Relative frequency (number in brackets) of disfluency types and within-word localization of disfluencies during spontaneous speech for each of the three test sessions.

\begin{tabular}{lccc}
\hline & $\begin{array}{l}\text { 1st test session } \\
\text { (544 syllables) }\end{array}$ & $\begin{array}{c}\text { 2nd test session } \\
(1021 \text { syllables })\end{array}$ & $\begin{array}{c}\text { 3rd test session } \\
\text { (754 syllables) }\end{array}$ \\
\hline Disfluency type & $81 \%(147)$ & $7 \%(1)$ & $9 \%(1)$ \\
$\quad$ Sound repetitions & $1 \%(1)$ & $27 \%(4)$ & $9 \%(1)$ \\
Syllable repetitions & $3 \%(6)$ & $13 \%(2)$ & $45 \%(5)$ \\
Word repetitions & $10 \%(19)$ & $13 \%(2)$ & $27 \%(3)$ \\
Prolongations & $5 \%(9)$ & $40 \%(6)$ & $9 \%(1)$ \\
Blocks & & & $91 \%(10)$ \\
Within-word disfluency localization & $88 \%(161)$ & $93 \%(14)$ & $0 \%(0)$ \\
Initial & $12 \%(21)$ & $0 \%(0)$ & $9 \%(1)$ \\
Medial & $0 \%(0)$ & $7 \%(1)$ & \\
Final & & &
\end{tabular}




\subsubsection{Naming test}

D. scored 51/60 on the Boston Naming Test (Kaplan et al., 1983; Mariën et al., 1998) which is within the normal range based on available normative data for adults. This was consistent with the observations made during the test session.

\subsubsection{Telephone follow-up}

Three months following the first testing session, a follow-up telephone call was made by the first author. D. reported that he went back to school after the summer break and that rehabilitation frequency was reduced to once a week. D. explained that he had improved on all aspects during the last months. His motor abilities had significantly improved and he was now mostly reading texts during the speech and language therapy sessions. The stuttering only occurred in the evenings or when he was tired. D.'s mother told that the stuttering had largely resolved after approximately one month of intensive therapy. She added that the morning of the follow-up call D. was ill and stuttered a little bit. She also reported hearing him use acquired fluency techniques (e.g. slower speaking rate and monitoring of his speech) when speaking. It was obvious during the telephone conversation that $\mathrm{D}$. was using these techniques during speech, which sounded unnatural. He was clearly monitoring his speech continuously and spoke in a slow way. During the conversation no stuttering was observed.

\subsection{Second test session (age: 17 years 1 month)}

\subsubsection{Stuttering frequency}

D. and his mother reported that his stuttering was now completely absent. This was obvious during the testing session, where his stuttering frequency did not exceed $1 \%$ of stuttered syllables during spontaneous speech. Similarly, D. was completely fluent during reading, naming days of the week, counting and singing (see Table 1 ).

\subsubsection{Disfluency types and localization}

Of the 15 stutters observed during conversation, 6 (40\%) were blocks and 4 (27\%) were one-unit syllable repetitions. Two disfluencies were prolongations and two other were repetitions of monosyllabic words. One sound repetition was present (see Table 2). Only one disfluency occurred at the end of a word (e.g., 'gaat-t' (goes)), all other disfluencies were observed in word initial positions.

\subsubsection{Secondary behaviors}

While his speech was essentially fluent, D. still showed what appeared to be secondary behaviors, such as restarting parts of sentences, lifting his eyebrows, turning his eyes upwards, and watching his hands while speaking. He occasionally started a word with a different sound (e.g., 'v-tien' (ten)) or interjected a sound during a stutter (e.g., inserting a schwa vowel as in 'bezig-ə-zijn' (being busy)). His speech still sounded somewhat unnatural during the second test session. He often paused between sentence boundaries and took a breath before continuing the conversation or the reading of the text. He talked carefully and at a relatively slow speaking rate.

\subsubsection{Emotions and attitudes}

D.'s scores on the questionnaires were all within the range of non-stuttering subjects. On the Behavior Checklist only the following two behaviors were checked: 'stop before saying a word that is often difficult to pronounce' and 'stop in the middle of a word that is often difficult to pronounce'.

\subsubsection{Stuttering severity}

His stuttering severity, calculated with the SSI-3 was below percentile 1, which suggested an absence of stuttering.

\subsubsection{Naming test}

Consistent with the first testing period, his score on the Boston Naming Test was within normal limits. 


\subsection{Third test session (age: 18 years 1 month)}

\subsubsection{Stuttering frequency}

Similar to the second test session, D. had a stuttering frequency of $1 \%$ (11 stutters) during spontaneous speech and did not evidence any stuttering during reading, counting and singing (Table 1).

\subsubsection{Disfluency types and localization}

The majority of D.'s disfluencies now consisted of repetitions of monosyllabic words (5 stutters, $45 \%$ ), followed by prolongations ( 3 stutters, $27 \%$ ), and repetitions of sounds, repetitions of syllables and blocks (one each, 9\%). All but one stuttering moment now occurred in the word initial position. One final sound repetition (e.g., 'nooit-t' (never)) was observed (Table 2).

\subsubsection{Secondary behaviors}

Clinical observation revealed that D. still used revisions, lifted his eyebrows, turned his eyes upwards and looked away during speech.

\subsubsection{Emotions and attitudes}

His scores on the questionnaires were all within the range of non-stuttering subjects. D. selfreported that he moved his hand and fingers while speaking and sometimes used gestures instead of speaking.

\subsubsection{Stuttering severity}

The stuttering severity calculated with the SSI-3 was below percentile 1 .

\section{Discussion}

Several cases of patients with rotavirus infection who showed similar characteristics as our patient have been reported in the literature. For example, it has been reported that rotavirus gastroenteritis can accompany some neurological disorders, including encephalitis/encephalopathy or seizures. These neurological symptoms occur in approximately $2-5 \%$ of patients with rotavirus gastroenteritis (Shiihara et al., 2007). Shiihara et al. (2007) published a case report of a 4;6-year-old boy who started to speak disfluently 6 days after detection of a rotavirus antigen. The MRI, EEG, routine hematology, blood chemistry and cerebrospinal fluid showed no abnormalities. He did not show a meningeal sign, walked with wide-base gait, experienced hand tremor, muscular hypotonia, slow speech and dysarthria. An MRI performed on day 29 showed bilateral cerebellar cortical lesions. On day 100 his gait was no longer ataxic but he still presented with slow speech, dysarthria and hand tremor. A second patient has been reported by Nigrovic, Lumeng, Landrigan, and Chiang (2002). Their patient was a 3-year-old girl who was admitted to the hospital with a 2-day history of vomiting and diarrhea. On the day of admission to the hospital, she abruptly stopped speaking. The blood count, head CT, cerebrospinal fluid, MRI and electroencephalogram all showed normal findings but a stool sample tested positive for rotazyme. One week later a second MRI showed bihemispheral cerebellar enhancement. Five months after the infection she had age-appropriate language but still walked with a wide-base gait. These two case reports represent children with cerebellar encephalitis following a rotavirus infection. In both of the cases the encephalitis was not visible during the initial medical examinations but was only seen after successive MRIs were performed. Comparable to D.'s case they had problems with speech and language (disfluent speech and mutism) and gait disturbances and made a slow neurological recovery.

In addition, Chen and Peng (1993) have described a 30-year-old woman who developed a sudden onset of stuttering in the early stage of Japanese B encephalitis. Three days after the onset of the disease she stuttered during conversation. Reiteration occurred mainly in the initial sentence position and was also present during reading, singing and repetition. There was no secondary movement of the face or mouth during the repetitions. Her stuttering persisted for 1 week and subsided spontaneously. Cranial CT-scan, EEG and electrodiagnostic studies revealed no definite focal abnormality.

The accurate diagnosis of encephalitis can be difficult. The cerebrospinal fluid and brain scans can be normal in many patients with proven Herpes Simplex Encephalitis and often the correct diagnosis can 
be confirmed only by brain biopsy (Whitley et al., 1982). Townend, Hanson, Sturm, and Whyte (2005) report that CT-scans are often normal during the first 2-3 days of the illness. They report MRI to be the best imaging technique to show possible changes within the first 2 days.

With regard to the localization of the encephalitis, it is known that neurogenic stuttering can occur following lesions in almost every site of the brain (De Nil et al., 2008), including the cerebellum. Yeoh et al. (2006) report the case of a 12-year-old boy with a mild closed head injury who showed cerebellar dysfunction and stuttering after the injury. All of his symptoms resolved spontaneously within $24 \mathrm{~h}$.

Although analogies between D.'s symptoms and the published case reports discussed earlier suggest a neurogenic cause of the speech and motor problems in our patient, a psychogenic component cannot be totally excluded. In D.'s case the diagnosis of encephalitis has not been confirmed by brain scans. Furthermore, the report by the neurologist mentioned inconsistencies in his behaviors when he was not aware of the observations. The fact that differential diagnosis between neurogenic and psychogenic stuttering can be problematic is well known in the acquired stuttering literature (Baumgartner, 1999; Roth et al., 1989).

Mahr and Leith (1992) have proposed a set of criteria to diagnose stuttering as a conversion reaction. According to these authors, all of the following defining criteria should be present before diagnosing someone as having psychogenic stuttering: 1) change in speech pattern suggesting stuttering; 2) relationship to psychological factors, as evidenced by the onset of symptoms associated with emotional conflict, the apparent symbolic significance of symptoms, and/or the presence of primary or secondary gain; and 3) absence of organic etiology. In addition, at least one of the following associated symptoms should be present: 1) past history of mental health problems; 2) atypical features, such as stereotyped repetition of initial or stressed syllables of words; speech pattern not affected by choral readings, white noise, or trial of delayed auditory feedback; no islands of fluency; or no secondary symptoms, no avoidance, and no attempts to inhibit stuttering; 3 ) la belle indifference. In our patient, the first defining criterion is present (change in speech pattern suggesting stuttering), as well as one associated symptom (the presence of atypical features, e.g. no islands of fluency during the first test session). However, the other defining and associated criteria do not appear to be present.

Other authors have suggested that the effectiveness of therapy can be a characteristic of psychogenic stuttering (Roth et al., 1989). In these patients, stuttering often has been reported to resolve during the initial evaluation or within the first therapy sessions (Baumgartner, 1999). For our patient, his stuttering was reported to improve spontaneously in the first weeks following a peak in his neurological symptoms. After therapy was started, it still took one month of daily speech therapy sessions before stuttering was absent in normal daily activities. Even then, D. still had an unnatural speech pattern characterized by slow speech and continuously monitored fluency.

In comparison, Helm-Estabrooks (1999) has suggested the following diagnostic criteria for neurogenic stuttering: 1) disfluencies occur on grammatical words nearly as frequently as on substantive words; 2 ) the speaker may be annoyed, but does not appear anxious; 3 ) repetitions, prolongations and blocks do not occur only on initial syllables of words and utterances; 4 ) secondary symptoms such as facial grimacing, eye blinking, or fist clenching are not associated with moments of disfluency; 5) there is no adaptation effect; and 6) stuttering occurs relatively consistently across various types of speech tasks.

Although these criteria may be helpful in making the differential diagnosis between neurogenic and developmental stuttering, not all of these criteria are of equal value for identifying patients with neurogenic stuttering. For example, the absence of adaptation and secondary behaviors do not seem to be a reliable differential criterion (Theys et al., 2008). When we exclude these two criteria, we observe that D. shows three of the four characteristics of neurogenic stuttering: the presence of annoyance but absence of anxiety around stuttering; stuttering that occurs relatively consistent across various types of speech tasks; and, repetitions, prolongations and blocks that do not occur only on initial syllables of words and utterances. Although D. did demonstrate some word final disfluencies, these were clearly very infrequent and constituted only a very small percentage of his overall disfluencies. Indeed, only 2 such instances were observed during spontaneous speech. This observation is in keeping with previous suggestions that final word disfluencies are infrequently observed in neurogenic stuttering (De Nil et al., 2008). It should also be noted that during the first test session, D. demonstrated a high frequency of disfluencies during all speaking situations, including more automatic speech tasks such as naming 
the days of the week, counting and singing which typically induce higher levels of fluency in developmental stuttering. During later test sessions, as his overall fluency increased, the number of disfluencies during these speaking tasks showed a parallel decrease. The fourth criterion, stuttering on grammatical words nearly as frequently as on content words, was not applicable to D.'s speech pattern.

\section{Conclusion}

The current case description represents an atypical patient with acquired stuttering. Not only the age at the onset of the stuttering is unusual, but also reports of stuttering after cerebellar involvement and after encephalitis are infrequent.

Although psychological involvement cannot be totally excluded, a neurological explanation of the symptoms seems likely and multiple analogies with previously described case studies are present. We therefore believe that D.'s problems are of neurogenic origin but that the presentation of his problems might have been exacerbated by environmental stressors. As is illustrated by this case, the potential role of the cerebellum in the neural control of speech fluency deserves further study. Previous brain imaging studies (De Nil, Kroll, \& Houle, 2001; Fox et al., 2000) have highlighted the potential importance of cerebellar involvement in developmental stuttering. This hypothesis is further supported by the current case study which confirms that cerebellar dysfunction also may result in stuttering behavior in older children and adults. This suggests that it may be of interest to investigate the presence of speech disfluencies in persons with ataxic dysarthria and other cerebellar syndromes, and to correlate the presence and severity of stuttering behavior with data from functional and structural cerebellar imaging.

Whatever the cause of the acquired stuttering, it is clear from D.'s case as well as from other case reports that intensive speech therapy in these patients may assist in, if not be required for, recovery of speech fluency.

\section{Acknowledgements}

We would like to thank D. and his parents for their cooperation in this study. We recognize the help of D.'s neurologists, psychiatrists and speech and language therapists in collecting the necessary information.

\section{References}

American Psychiatric Association. (2000). Diagnostic and statistical manual of mental disorders, text revision (DSM-IV-TR $\left.{ }^{\mathrm{TM}}\right)(4 \mathrm{th}$ ed.). Washington, DC: American Psychiatric Association.

Baumgartner, J. M. (1999). Acquired psychogenic stuttering. In R. F. Curlee (Ed.), Stuttering and related disorders of fluency (2nd ed.). New York: Thieme.

Bloodstein, O. (1995). A handbook on stuttering (5th ed.). New York: Delmar Learning.

Boey, R. (2000). Stotteren: detecteren en meten. Leuven: Garant.

Brutten, G. J., \& Vanryckeghem, M. (2003). Behavior Assessment Battery. Onderzoeksinstrument voor stotteren. Nederlandse vertaling: Nadja Brocatus. Destelbergen: SIG.

Byrne, A., Byrne, M., \& Zibin, T. (1993). Transient neurogenic stuttering. International Journal of Eating Disorders, 14, 511-514.

Chen, W.-H., \& Peng, M.-C. (1993). Acquired stuttering in a patient with encephalitis. Kaohsiung Journal of Medical Sciences, 9, $183-185$.

Cordes, A. K., Ingham, R. J., Frank, P., \& Ingham, J. C. (1992). Time-interval analysis of interjudge and intrajudge agreement for stuttering event judgments. Journal of Speech and Hearing Research, 35, 483-494.

De Nil, L. F., Kroll, R. M., \& Houle, S. (2001). Functional neuroimaging of cerebellar activation during single word reading and verb generation in stuttering and nonstuttering adults. Neuroscience Letters, 302, 77-80.

De Nil, L. F., \& Rochon, E. (2008). Adult-onset neurogenic stuttering. In R. Jokel, \& M. R. McNeil (Eds.), Clinical management of sensorimotor speech disorders (2nd ed.). New York: Thieme.

Fox, P. T., Ingham, R. J., Ingham, J. C., Zamarripa, F., Xiong, J.-H., \& Lancaster, J. L. (2000). Brain correlates of stuttering and syllable production: a PET performance-correlation analysis. Brain, 123, 1985-2004.

Helm-Estabrooks, N. A. (1999). Stuttering associated with acquired neurological disorders. In R. F. Curlee (Ed.), Stuttering and related disorders of fluency (2nd ed.). New York: Thieme.

Kaplan, E., Goodglass, H., \& Weintraub, S. (1983). Boston naming test (2nd ed.). Austin, Texas: Pro-Ed.

Mahr, G., \& Leith, W. (1992). Psychogenic stuttering of adult onset. Journal of Speech and Hearing Research, 35, $283-286$.

Mariën, P., Mampaey, E., Vervaet, A., Saerens, J., \& De Deyn, P. P. (1998). Normative data of the Boston naming test in native Dutch-speaking Belgian elderly. Brain and Language, 65, 447-467. 
Michel, V., Burbard, P., Taillard, J., Gaida, T., Joseph, P. A., Duché, B., et al. (2004). Stuttering or reflex seizure? A case report. Epileptic Disorders, 6, 181-185.

Movsessian, P. (2005). Neuropharmacology of theophylline induced stuttering: the role of dopamine, adenosine and GABA. Medical Hypotheses, 64, 290-297.

Nass, R., Schreter, B., \& Heier, L. (1994). Acquired stuttering after 2nd stroke in a 2-year-old. Developmental Medicine and Child Neurology, 36, 73-78.

Nigrovic, L. E., Lumeng, C., Landrigan, C., \& Chiang, V. W. (2002). Rotavirus cerebellitis? Clinical Infectious Diseases, 34, 130.

Riley, G. (1994). Stuttering severity instrument for children and adults (3rd ed.). Austin, Texas: Pro-Ed.

Roth, C. R., Aronson, A. E., \& Davis, L. J. (1989). Clinical studies in psychogenic stuttering of adult onset. Journal of Speech and Hearing Disorders, 54, 634-646.

Shiihara, T., Watanbe, M., Honma, A., Kato, M., Morita, Y., Ichiyama, T., et al. (2007). Rotavirus associated acute encephalitis/ encephalopathy and concurrent cerebellitis: report of two cases. Brain \& Development, 29, 670-673.

Stes, R. (1999). Attitudemeting bij stotteren. Normering van de S-schaal in Vlaanderen. Antwerpen: CIOOSvzw.

Theys, C., van Wieringen, A., \& De Nil, L. F. (2008). A clinician survey of speech and non-speech characteristics of neurogenic stuttering. Journal of Fluency Disorders, 33, 1-23.

Townend, B. S., Hanson, J. A., Sturm, J. W., \& Whyte, S. (2005). Stroke or encephalitis? Emergency Medicine Australasia, 17, 401-404.

Whitley, R. J., Soong, S.-J., Linneman, C., Liu, C., Pazin, G., \& Alford, C. A. (1982). Herpes simplex encephalitis: clinical assessment. The Journal of the American Medical Association, 247, 317-320.

Yeoh, H. K., Lind, C. R. P., \& Law, A. J. J. (2006). Acute transient cerebellar dysfunction and stuttering following mild closed head injury. Child's Nervous System, 22, 310-313. 